\title{
Playing with Representations: How Do Kids Make Use of Quantitative Representations in Video Games?
}

\author{
Tom Satwicz $\cdot$ Reed Stevens
}

Published online: 11 November 2008

(C) Springer Science+Business Media B.V. 2008

\begin{abstract}
This paper describes the use of quantities in video games by young people as part of a broader effort to understand thinking and learning across naturally occurring contexts of activity. Our approach to investigating the use of quantities in game play is ethnographic; we have followed eight children over a six-month period as they play their own games at home. The data set is composed of video recordings and artifact-based interviews. The concept of disciplined perception is used to understand how quantities are coordinated during game play. The current study shows young people using quantities in games to make predictions and organize their actions based on those predictions. Some ideas based on the study's findings for using video games in school are discussed.
\end{abstract}

Keywords Representations - Everyday mathematics · Video games · Learning $\cdot$ Ethnography $\cdot$ Distributed cognition $\cdot$ Disciplined perception

\section{Introduction}

Analyzing the creation and use of representations is helpful for understanding quantitative reasoning. Consequently, researchers have investigated how young people create and use representations to get at their understanding of various scientific and mathematical topics such as proportion, space, similarity, motion, time, multiplication, and addition (Cobb et al. 1992; diSessa et al. 1991; Enyedy 2005; Izsák 2004, 2005; Kaput 1998; Leinhardt et al. 1990; Lehrer et al. 2002). One of the major goals of representations research is to capture and improve upon students' quantitative reasoning in classrooms. At the same time we have come to find that "transferring in" and "transferring out" of situations is critical to

T. Satwicz (ه)

Learning and Performance Support Laboratory, University of Georgia, 611 Aderhold Hall, Athens, GA 30605, USA

e-mail: tsatwicz@uga.edu

R. Stevens

Learning Sciences Program, University of Washington, Seattle, WA, USA

e-mail: reedstev@u.washington.edu 
learning (Bransford and Schwartz 1999; Schwartz et al. 2005). In other words, if we are concerned with helping young people develop quantitative competencies that they can use in real world settings, then we need to attend to what they are able to do with quantity in their lives outside of classrooms. This requires research methods for studying out of school uses of quantity. In this paper we apply a set of methods designed to understand how young people use quantity in video games.

For some time the learning sciences have highlighted the importance that knowledge developed outside of school plays in the development of new concepts and practices (Bransford et al. 2000). For instance, Vygotsky (1962) contended that the "the development of scientific and everyday concepts" (p. 162) were related and built on each other.

We believe that the two processes - the development of spontaneous [everyday] and of nonspontaneous [mathematical and scientific] concepts - are related and constantly influence each other. They are parts of a single process: the development of concept formation, which is affected by varying external and internal conditions but is essentially a unitary process, not a conflict of antagonistic, mutually exclusive forms of thinking (p. 157).

Vygotsky's basic move, relating the development of formal knowledge and informal knowledge, is consistent with the approach we take in this paper. However, like others (Greenfield et al. 1994; Ochs et al. 1992; Stevens and Hall 1998), our work parts ways from Vygotsky's hypothesis that scientific thinking is necessarily an outcome of formal schooling.

It is easy to pass off everyday experiences as inconsequential math or science (Palinscar 1989), however we find the persistent use of quantity in video games to be an important dimension of young people's activities. Young people develop the ability to interpret, create, and use representations apart from instruction (diSessa et al. 1991; diSessa and Sherin 2000), raising the question of where these quantitative competencies originate. The ethnographic tradition insists that such questions are answered with an analysis that looks at specific uses of quantity in everyday, informal contexts. Consequently, we have selected a context that is flush with representations and where children spend a great deal of time (Lenhart et al. 2008), explicating video game play as a possible source.

We approach the use of representations in video games as though there are quantitative practices employed (Stevens 1999). The term 'quantitative practice' is used in reference to how people make use of quantities in their everyday activities (Beach 1995; de la Rocha 1986; Lave 1988; Scribner 1997; Stevens 1999; Stevens and Hall 1998). We withhold the terms 'mathematical practice' and 'scientific practice' because of their relation to formal disciplines that are closely tied to educational and professional contexts. Our withholding the terms mathematical and scientific is not meant to diminish similarities between how quantities are used in everyday life and how they are used in formal disciplines. Rather it is a means to attend to everyday practices without restricting ourselves to the concepts, artifacts, tools, and tasks that surround and make up the formal practices.

To varying degrees most (if not all) video games represent quantitative information to the player (see Fig. 1). We use the term quantitative representation in reference to the various ways that quantities appear in particular media and in conventional forms (Saxe 1991). Quantities can take many forms such as a graph, a vector, or a number; they can also take the form of a pitch or rhythm that indicates extent or a bar that indicates "life." These forms are stored and appear in different kinds of media including digital screens, print publications, and embedded audio. As Fig. 1 indicates, video games represent quantities in forms such as numbers, bar graphs, tables, icons, and colors. Additionally, the object of 

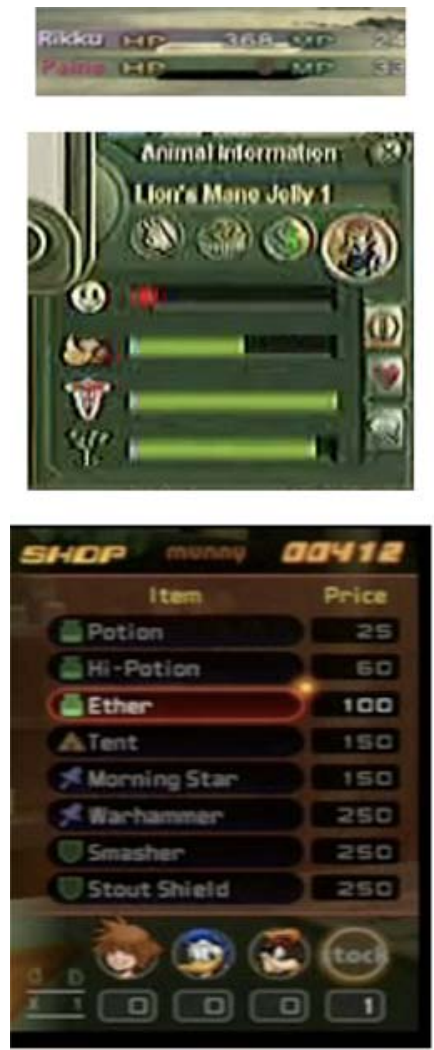
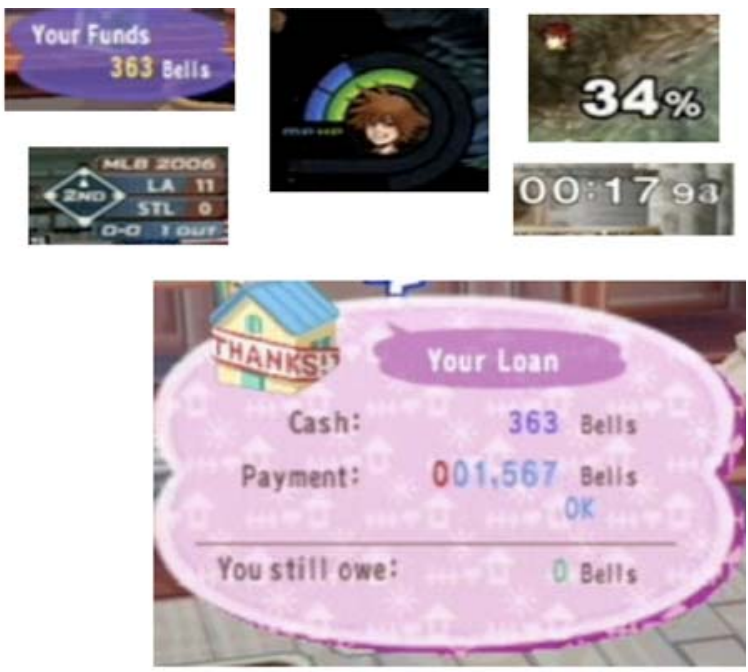

\begin{tabular}{|c|c|c|c|}
\hline Fashion Found & $0 / 76$ & $0 \%$ & \multirow{2}{*}{$\begin{array}{c}\text { Cumulative } \\
\text { Aspiration } \\
\text { Points }\end{array}$} \\
\hline Recipes Learned & $4 / 24$ & $26 \%$ & \\
\hline Objects Unlocked & $6 / 50$ & $12 \%$ & \\
\hline Promotions Earned & $0 / 90$ & $0 \%$ & 1.580 \\
\hline Careers Completed & $0 / 10$ & $0 \%$ & \multirow{2}{*}{$\begin{array}{l}\text { Overall } \\
\text { Completion }\end{array}$} \\
\hline Skill Points Earned & $1 / 70$ & $1 \%$ & \\
\hline Stills At Maximum & $0 / 7$ & os & \multirow{3}{*}{$\equiv \%$} \\
\hline Sims Helped & Ons & os & \\
\hline Locations Discovered & $2 / 22$ & $16 \%$ & \\
\hline
\end{tabular}

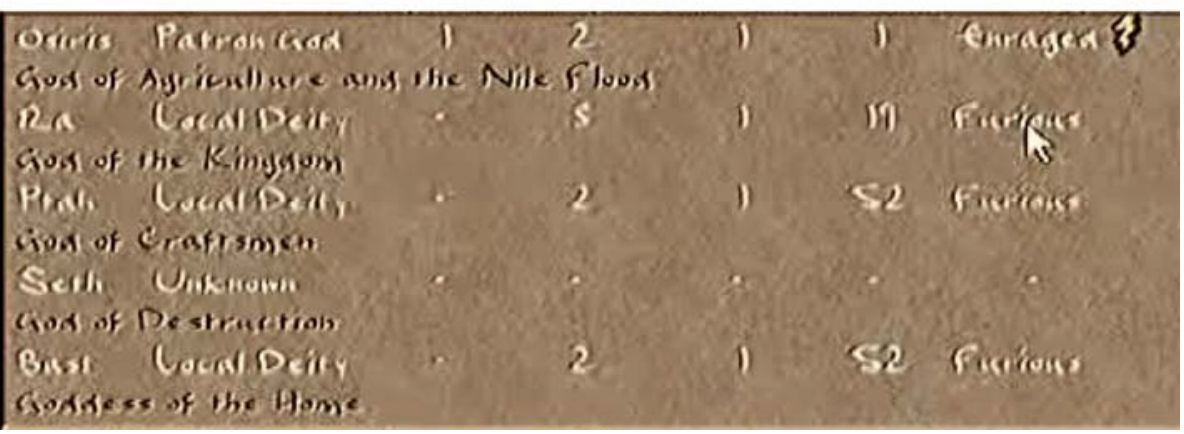

Fig. 1 Quantitative representations across different video games

many video games is expressed in quantitative terms such as obtaining a high score or reaching a particular level. From a design perspective quantification is typically an integral part of games. "A game is a system in which players engage in an artificial conflict, defined by rules, that results in a quantifiable outcome" (Salen and Zimmerman 2004, p. 81, italics in original). Across video games, designers use quantitative representations that follow common conventions like time, life, and money making it easier for players to move from one game to the next.

Studies that have investigated game play and STEM (science, technology, engineering, and mathematics) thinking and learning argue that the use of representations in games 
supports quantitative thinking. However, science and mathematics educators that have attended to different uses of representations may not find it all that surprising that representations in games lead to some quantitative thinking. What games research does offer is the argument that games are for the most part an enjoyable cultural activity. Young people (and adults) willingly engage with them on their own time; consequently it is held that STEM learning is embedded into a non-STEM activity and occurs with little effort or resistance. A challenge for games research is to understand the dimensions of quantitative thinking that occur within game play, where representations that are not standard in STEM disciplines are often used. An aspect of this challenge is to understand the extent to which integrating STEM topics and representations with the story line and action of a game influence quantitative thinking.

Nasir, Saxe, and others (Guberman and Saxe 2000; Nasir 2005; Saxe and Bermudez 1996) identified several ways in which social and material aspects of non-digital games support mathematical thinking. For instance, in the game of dominos, tiles represent a collection of numbers that are aligned in specific ways to score points, an additive and multiplicative process. Over time dominos players develop more sophisticated and complex goals like blocking opponents from scoring that require them to apply mathematical thinking to the game. While many of the game's functions in this case are mathematical, the various forms a dominos board takes are quite different from representations commonly seen in STEM disciplines. In other words, it is the changing nature of the game rather than a tight integration with STEM topics that provides an impetus for mathematical thinking.

Greenfield and colleagues (Greenfield 1994; Greenfield et al. 1994) conducted psychological experiments to test whether or not the inductive skills developed while playing video games transferred to scientific and technical representations. Their findings suggest game play leads to the development of skills for decoding and encoding iconic representations. The players they studied became more acute at understanding and interpreting images on the game screen as well as "animated demonstrations of circuits on a computer screen" (Greenfield et al. 1994, p. 65). Greenfield and colleagues positioned video games as part of a 20,000-year trajectory in which humans have increased the use of "symbolic codes external to the individual mind" (Greenfield 1994, p. 5). Their position was, in principle, that the effects of video games are independent of content. Playing video games develops skills for interpreting symbolic codes and, since as a society we continually rely on symbolic codes, Greenfield and colleagues argued that video games could have educational benefits.

More recently, Lowrie's (2005) case study of a seven year old boy playing the popular video game Pokémon argued that he navigated the game using maps built into the game, a strategy guide, and mental representations of the game's space. Through a set of interviews, the boy demonstrated an early understanding of scale and proportion prior to having been introduced to those concepts in formal education, suggesting that the game involves important quantitative practices. Lowrie then argued that the young boy's uses of mathematical concepts and processes while solving problems in the game was due in part to the social and personal relevance of the game in the young boy's life.

There are a variety of ways that games have been designed specifically for learning in STEM and other academic areas. An early and long-lived category consists of commercially available video games in which there is little or no relationship between the action or narrative of the game and academic topics (Ito 2008; Rieber 1996; Squire 2006). Mathblaster is frequently held as the prototypical example of this genre, because the game's action (shooting objects) has little to do with disciplinary mathematics. However, the game 
does represent mathematical forms as they are seen in school with some accuracy. It achieves this by layering a game on top of mathematical topics, which results in activity that is analogous to standard drill and practice pedagogies.

Researchers have also attempted to integrate STEM topics with the story line and action of games. For instance, Griffin et al. (1994) designed a game in which children count and line up chips on a set of number lines while answering questions about the position of various chips on the lines. In this particular example a specific mathematical representation, the number line, was used as the basis of a game. Griffin et al. argue that their games address specific gaps in children's internal representations of numbers and mathematical rules that govern relationships between numbers.

A set of studies conducted in the 1990s took a rather different approach to integrating STEM topics and game action by asking students and teachers to design content into video games (Kafai et al. 1998; Rieber 1996). In these situations students and teachers designed games that, for example, teach younger students about fractions. Kafai et al. (1998) found that both teachers and students adopted standard static mathematical representations of fractions in their initial designs. However, as the researchers introduced a set of conceptual design tools, such as having participants create games that did not ask questions, the game designs began to incorporate representations of fractions that are not standard in STEM disciplines. These non-standard representations were an integral aspect of a game's action. For instance, one game involved a beach scene that represented different proportions of people in and out of the water. Kafai et al. addressed the challenge of integrating STEM topics into games by switching the student role from players to designers. Mathematical thinking emerged as the now designers had to consider using non-standard representations as mathematical objects.

More recently researchers have attempted to integrate game action and STEM topics by simulating situations in such a way that players engage in inquiry projects (Barab et al. 2005, 2007; Nelson 2007; Squire et al. 2004; Squire and Klopfer 2007; Squire and Jan 2007). In these types of games and simulations, players are involved in scientific tasks that have social implications, like solving environmental problems. An important aspect of the simulations is the use of representations to present information to the player. At times these representations appear in standard STEM forms, while at other times they appear as nonstandard representations like hand written notes. The mixed forms help create conditions upon which young people discuss their meaning in class and engage with STEM topics.

The set of studies we described above, whether designed educational activities or the rare investigations into STEM topics within existing games, demonstrate that internal and external quantitative representations are an important aspect of game play. However, with respect to video games this previous work has for the most part had the methodological simplification of being able to design the tasks used for analysis. This, of course, does not invalidate their findings. In fact, these studies have been quite useful in helping us understand how games can be used in educational settings. However, we started this paper with a desire to understand young people's uses of quantity in naturally occurring conditions. Video games are a particularly challenging (and interesting) context to study in this respect because there is not a great deal of representing with voice, writing, or iconic gestural action. Our methodological challenge then is to attempt to root out quantitative understandings implicit in the game players' actions. The pay off for this kind of analysis is that it can give us analytic tools to determine what kinds of quantitative understandings young people bring to school, thereby helping advance the basic tenet of constructivism, namely that we must make sense of new knowledge construction against the backdrop of existing knowledge. 


\section{Data Sources and Methods of Analysis}

The data we present here is taken from a six-month ethnographic study of young people's game play that was conducted as part of a broader effort to understand how people think and learn across settings such as school, work, and home (Bransford et al. 2006; Stevens 2000a; Stevens and Hall 1998; Stevens et al. 2005, 2006, 2008). Research on learning in everyday non-school settings is vastly underrepresented in comparison to research that takes place in laboratories and schools (Bransford et al. 2006). This is especially striking when we consider that young people spend $79 \%$ of their waking hours in activities that occur outside of school (Bransford et al. 2000). Our decision to study game play, then, extended beyond a specific interest in video games and was influenced by the fact that gaming is how many young people choose to spend their time and consequently is an important part of their development (Stevens et al. 2008).

Our research team visited eight participants on a weekly basis in their own homes for six-months. We chose the specific population to represent a range in age (9-15), gender (4 boys and 4 girls), social configuration ( 2 sets of siblings, some participants played with friends while others played alone), and the type of games played. The participants selected and played their own games on their own systems, allowing for as naturally occurring conditions as possible during field visits. While the participants played, we video recorded activity that occurred in the room along with activity taking place on the game screen. Later, we synchronized the two images, "in-game" and "in-room," into a single file. The benefit of having both the in-game and in-room recordings is that we are able to attend to important in-room resources that are often left out of research on game play (Stevens et al. 2008). We began our analysis by content logging the recorded videos (totaling over 100 hours) with written descriptions of activity across the game and the room marked with specific instances for more detailed analysis (Goodwin and Goodwin 1998; Jordan and Henderson 1995; Stevens and Hall 1998). We then used the content logs to build cases in categories, like quantitative practices, as part of our comparative analysis of learning across settings.

The analysis on which we report here focuses on two cases. One of the cases comes from our observations of two brothers, Mikey (age 15) and Johnny (age 13). Mikey and Johnny frequently played together and sometimes included their younger sister Maddy (age 8) in an apprenticeship role (Lave and Wenger 1991; Stevens et al. 2008). Throughout our field visits Johnny and Mikey often played Super Smash Bros. Melee ("Melee" to use their shortened term), consequently our report pays particular attention to this game. In Melee two or more characters fight each other in battles until a predetermined set of conditions are met. The other case on which we report here comes from our observations of Vanessa (age 13) who despite having friends, an older brother, and a parent that play video games, most often played by herself during our visits. Vanessa frequently played Final Fantasy $X$ 2 (FF X-2), ${ }^{1}$ a role-playing game that involves an unfolding narrative based on the adventures of three characters.

We also draw on information gathered during exit interviews in which we asked participants to annotate images from video games as well as one minute of corresponding

\footnotetext{
${ }^{1}$ Super Smash Bros. Melee and Final Fantasy X-2 are representative of popular game genres and franchises. Both video games are among the best selling of all time (List of best-selling video games 2007). While reported sales (6 million Melee, 3 million FF X-2) are less than some popular online games such as World of Warcraft (10 million), they each retain a substantial presence in the video game market. Additionally, they are both played on console game systems, which are nearly ubiquitous in American homes. Their popularity allows for reasonable conclusions about the kinds of experiences game players have.
} 
video using Video Traces. ${ }^{2}$ We used this technique as a form of an artifact-based or elicited interview common in social sciences (Harper 1997; Stevens and Hall 1997; Wineburg et al. 2007). The purpose of using this technique is to draw out the participant's perspective on specific issues relevant to the analysis. Our observations led us to believe that there were moments when it was likely that the participants were using quantitative representations. We then selected video and still images from those moments for the interview. Because our participants often did not verbalize their reasoning while they played, this use of Video Traces proved to be an important aspect of our methodology. A more complete description of our interview procedure is available in the appendix.

\section{A Distributed Framework for Analyzing Game Play}

Our analysis draws on a distributed perspective of human activity (Bateson 1972; Becker 1982; Hutchins 1995a, b; Latour 1992, 1996; Satwicz and Stevens 2008). In using this perspective, we are expanding the boundary for the unit of cognitive analysis beyond the individual to include artifacts and people relevant to accomplishing a given task. Hutchins' (1995a, b) foundational analysis of this type demonstrated that cognitive properties often attributed to humans are better described as coordinated interactions within a socio-technical system. "This system-level cognitive view directs our attention beyond the cognitive properties of individuals to the properties of external representations and to the interactions between internal and external representations" (Hutchins 1995b, p. 287). Our analysis of quantitative practices is primarily concerned with the interaction, specifically coordination, of representations across mediums that are both internal and external to game players.

Typically, work from a distributed perspective analyzes relatively stable sets of practices among adults in work settings. However, recent studies have identified the question of how representational states are created and disrupted as a problem for both distributed cognition and the learning sciences (Hall et al. 2002, 2004; Stevens and Hall 1998). When appropriate we use Hutchins' definition of learning as "adaptive reorganization in a complex system" (Hutchins 1995a, p. 289). Our analysis then is designed to understand how young people adaptively reorganize internal and external representational mediums into coordinated states while playing games.

In our analysis, we focus on disciplined perception as a central component of how individuals bring representational states into coordination (Stevens 1999; Stevens and Hall 1998). Disciplined perception refers to discipline-specific practices that individuals learn and use in order to coordinate representations. We are expanding on previous research that has used this concept to explain how, across work and school settings, novices learn to appropriately "see" mathematical representations so that they can coordinate various artifacts and procedures to accomplish tasks (Stevens and Hall 1998). Disciplined perception, however, is applicable to any activity that involves specialized ways of interpreting perceptible information (c.f., Rose 2004). Professionals such as doctors, chefs, lawyers, and plumbers learn to perceive various artifacts (bodies, charts, documents, pipes, etc.) to make decisions and accomplish tasks (Stevens and Hall 1998). Our assumption, then, is that game players also have disciplined ways of interpreting game images. One of the challenges of this work is to uncover what disciplined perception looks like in this context as a stable practice then, if possible, as an active process of change.

\footnotetext{
${ }^{2}$ Video Traces is a computer-based medium that allows for annotation using talk, gesture, and drawing of video and still images (Stevens 2007; Stevens and Hall 1997).
} 


\section{Analysis}

We address the challenge of documenting young people's everyday use of quantitative representations in video games by looking within our marked instances for two particular features: patterns of activity and emergent uses of representations. Beyond allowing us to see a repeated behavior on the part of our participants, analyzing specific patterns in the data set evoke questions about how the practice has stabilized and its function. Emergent uses raise questions about the reorganization of resources, internal and external to the player. Both are useful for understanding how quantitative representations are used because they disclose young people's implicit understandings of their function within the game.

In each case we pay particular attention to representations of "life" to allow for comparisons between cases. In many places the quantity is not referred to as life, but by terms such as "hit points," "health," or "damage." Whatever the specific term the quantity indicates how much life a character in the game has at a particular moment. The following conversation $^{3}$ between Johnny and Mikey suggests that life is probably the most ubiquitous quantitative representation in video games. Life varies in appearance across games (see Fig. 2) and its use is dependent on how the player coordinates it with other aspects of the game such as timers, tasks, characters, and moves. Life can be used to determine whether the game or portion of the game has ended or by the player to make decisions about which course of action is appropriate at a particular moment in the game.

\section{Transcript 1}

1. Johnny: Can you image a video game without life bar?

2. Mikey: Ah yeah it'd be kind of weird.

3. Researcher ${ }^{4}$ : Yep.

4. Mikey: Well Animal Crossing doesn't show you life, but then again you don't need it because you're not fighting (3 sec.) you're living a peaceable existence.

5. ((Play continues and Mikey shows Johnny how to do a particular move.))

6. Researcher: So do you guys use the life stuff a lot?

7. Johnny: Huh?

8. Researcher: Do you look at it much while you're playing?

9. Mikey: The what? Oh the life stuff.

10. Johnny: You check how much your opponent's getting killed.

11. Mikey: Yeah and you can tell if you're gonna die too $(2 \mathrm{sec}$.), if you're really really gonna die you just kind of surrender.

\section{[Johnny and Mikey 2006-January-06 00:34:24.21]}

\subsection{Case One: Johnny and Super Smash Bros. Melee}

In our first case we lay out how three different quantitative practices taken from our analysis of Johnny and Mikey's play of Melee were enacted in relation to the boys' disciplined perception of game play. The practices are presented in order of increasing complexity. First we show how Johnny used single quantities to organize his game actions.

\footnotetext{
3 Our transcripts display talk, in-room activity, and in-game activity. Double parentheses are used to mark action on the part of our participants whether in-game or in-room.

4 Throughout the paper "researcher" refers to the first author.
} 


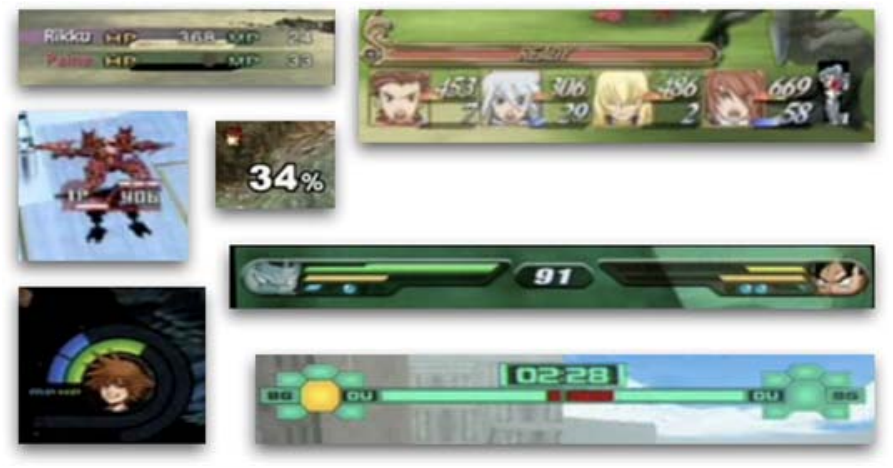

Fig. 2 Some life representations include integers, percentages, or bars

Then we describe an instance in which Johnny and Mikey coordinated three separate yet equivalent quantities to make inferences upon which they organized their game actions. Finally we show how Johnny coordinated quantities in order to project future quantitative states in the game that organized his immediate actions, in this case restarting the game.

In fighter style games like Melee each player controls one character in battles against other players or the computer. To attack another character the player inputs "moves" by pressing specific button combinations on the controller. "The object of Super Smash Bros. Melee is to attack your opponents and send them flying from the field of battle" (Super Smash Bros. Melee: Instruction booklet 2001, p. 6). To novices and untrained observers entering moves may seem like button mashing, however each move has a specific purpose and in a difficult battle certain moves can give a player a distinct advantage. Appropriately interpreting the representations on the screen is one aspect of knowing when to use the right move to "finish off" an opponent.

The form of Melee's life representation shapes its function and use by game players. Fighter games typically represent life with a colored bar that decreases as the battle progresses. However, in Melee the life representation has two parts, an icon and a percentage, that together make use of two separate numeral systems each of which can serve a separate function for the player (see Fig. 3). The icons, which are positioned above the percentage, indicate how many lives each character has left-these decrease as the battle progresses. The icons act as a base one or unary numeral system, which has the advantage of clearly displaying how many lives are left (in Fig. 3 each of the characters has one life left). However, unary systems cannot represent non-integer values with a radix or decimal point and so the icons do not tell the player how close a character is to losing a life. The percentage picks up for the icons' lack of function and tracks the character's damage- this increases as the battle progresses. In Transcript 2 we see that both Mikey's explanation and Melee's instruction booklet indicate that as the percentage increases the corresponding character is weakened and easier to throw off the screen. The player then can use the percentage as an indication of when to use "finishing" moves. Consequently, for the player to coordinate the right moves he must be able to determine when the representation indicates his opponent is weak.

\section{Transcript 2}

Mikey: If it passes a hundred you get easier to throw off the screen, so every time you get hit it goes up.

[Johnny and Mikey 2005-07-14_00:23:48.16] 
The distance enemies get sent flying is proportional to the amount of damage they have taken. Try to raise your foe's damage percentage as high as possible before attempting finishing blows.

(Super Smash Bros. Melee: Instruction booklet, 2001, p. 7)

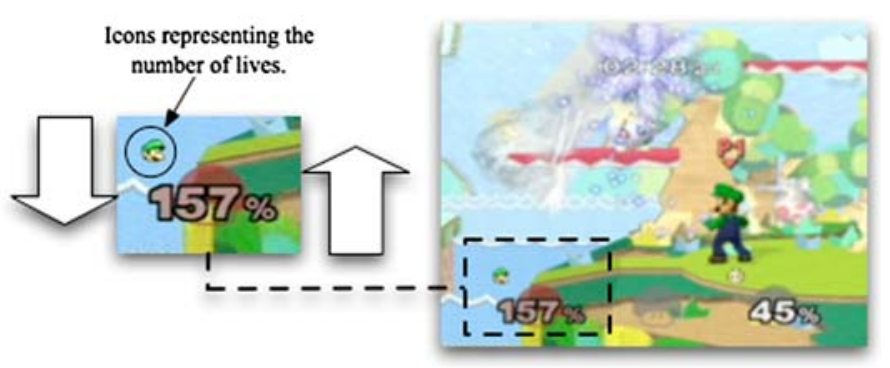

Fig. 3 A typical Melee screen image is on the right. On the left is an example of a Melee life representation. The number of icons above the percentage decrease as the character loses life. The percentage increases as the character loses life. Without the life representation it is not possible to tell which character is winning or when to use a finishing move

\subsubsection{Quantitative Practice I: Using Single Quantities to Organize Actions}

In our first quantitative practice Johnny played the game much as we might expect; he followed the life representations individually and used his finishing moves when an opponent reached a weakened state. Johnny's attempt to complete a particular challenge in the single player "events" mode ${ }^{5}$ of Melee was indicative of this quantitative practice. In this event, called Trophy Tussle 3, Johnny first selected his character then he had to defeat three other characters, determined by the game, in a single three-minute battle. In Fig. $4^{6}$, we have selected screen images from the visit during which Johnny completed the Trophy Tussle 3 event. The images correspond with his talk as he beat each character and include our drawings, which highlight how the quantities were used. Johnny's statement that he must beat them "one at a time" indicates that he tracks the quantities individually. He then used his character and available moves to attack his three opponents individually. The empty spaces in Fig. 4, where the percentages and icons had appeared for characters that he already defeated, demonstrate that he attacked the opponents separately.

\subsubsection{Quantitative Practice II: Coordinating Quantities to Organize Actions}

Our next quantitative practice builds on the first to demonstrate how Johnny and Mikey coordinated all of their opponents' life quantities in order to determine when to use a specific finishing move. This quantitative practice is an example of a disciplined perception in which inferences and actions are based on the coordination of different quantities. Additionally, the instance shows Mikey making inferences based on quantities he was monitoring that were not displayed on the screen. This is a more complex practice than the

\footnotetext{
5 Melee has several different modes of play. Johnny and his siblings typically played either the multiplayer "vs." mode against each other or the events mode.

${ }^{6}$ Because our data set includes a significant amount of visual information (i.e., video recordings) we have combined images from our participants' games with transcripts of their activities.
} 

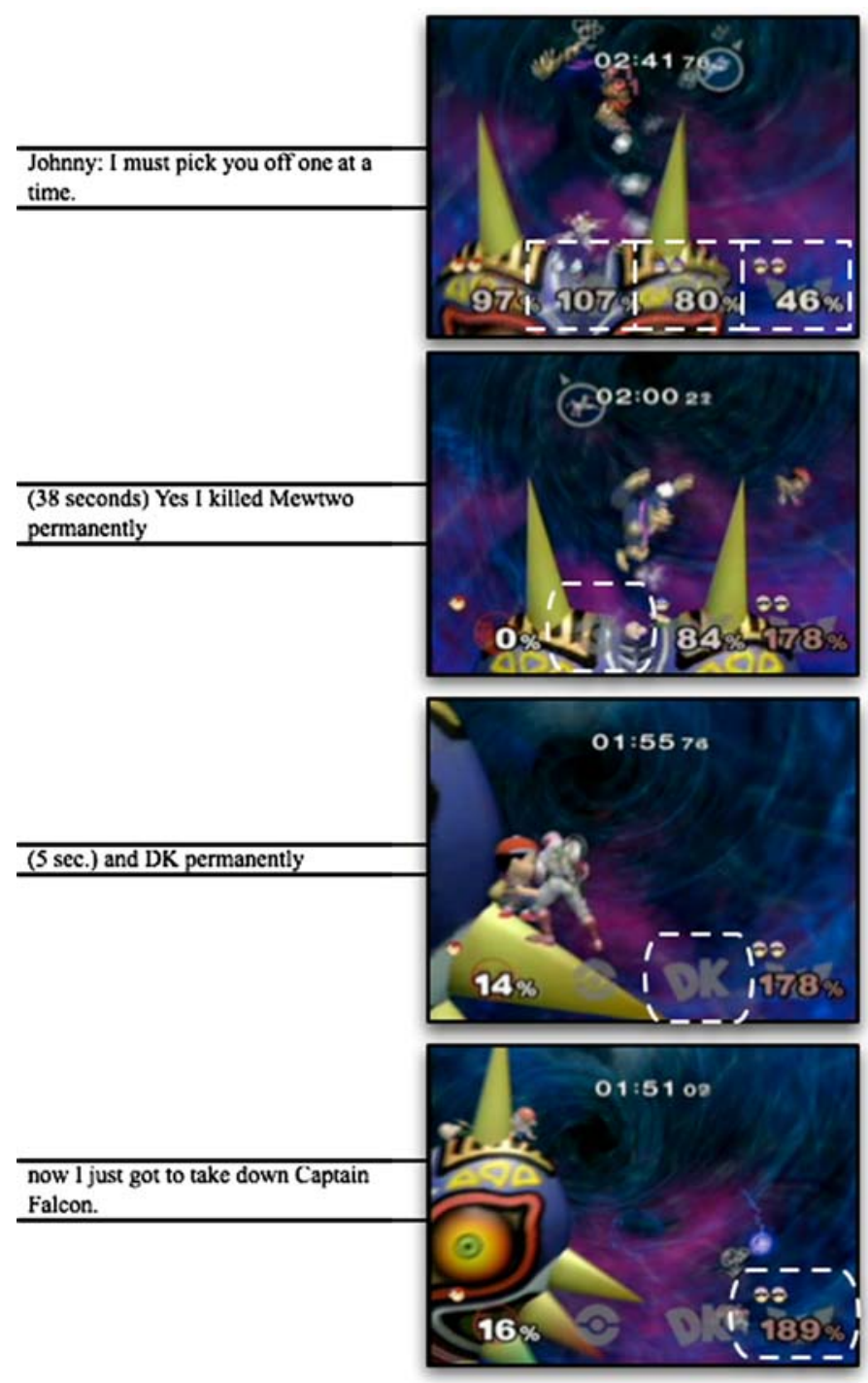

Fig. 4 Johnny and Mikey 2005-11-17 01:21:01.06

one described in the first section in that it involves the organization of actions based on the coordination of multiple quantities.

The instance we use to demonstrate this quantitative practice was an occasion in which Johnny and Mikey struggled to complete the same Trophy Tussle 3 event described above. Johnny attempted the event unsuccessfully 15 times over a period of 10 minutes after Mikey had attempted it 3 times. Figure 5 demonstrates their use of the life representation. At that particular moment Johnny was controlling a character named Jigglypuff while Mikey sat next to him and watched the game. Mikey then suggested to Johnny that he refrain from using Jigglypuff's "instant KO" until the other three characters had "about 70 
damage each" (line 3). To support his recommendation to do so, Mikey claimed that he had "figured out" the amount of damage given by an attack. Since the screen did not display the characters' previous damage score and there were not any other representations of life present outside of the game we infer Mikey was mentally tracking changes in life. Mikey's thinking was likely a simple comparative subtraction process; he remembered the previous amount of life then compared it with the amount of life displayed on the screen. Mikey was monitoring quantities beyond what is on the screen. Mikey's reference to 70 damage also indicates that he had identified a specific amount of damage in order for the finishing move to work. The action then, using the finishing move, was based on waiting for three quantities to reach a particular level.

The instance in Fig. 5 also provides evidence of Johnny and Mikey's coordination of the life representations. Their perception of the representations was not displayed on the screen, however it is present in their talk and Johnny's interaction with the game. Mikey's reference to "them" as opposed to specific characters at this moment reflects a view of the three opponents' life representations as a combined set that needed to be eliminated in order to beat the event (lines 1 and 3). Their perception of the representations is based in Johnny's attempt to use a move called "instant KO" that allows Jigglypuff to knock out (i.e., KO) several characters at one time. Mikey was suggesting that Johnny avoid the opponents until they damage each other and then use instant $\mathrm{KO}$ to beat them all at one time (line 3). We have drawn a dashed line over the screen shot attached to Fig. 5 at the moment of Mikey's comment to highlight their coordination of the quantities.

Leading up to Mikey's suggested strategy two other statements were made that indicate the boys viewed the opponents' representations as a combined set (see Fig. 6). Johnny's description of the game's status in Fig. 6 contained a predeterminer, "all," that he used to join the three separate representations. Mikey's statement in Fig. 6 includes a suggestion to Johnny that he restart the event because he had not made enough progress on reducing life across all of the characters.

In this instance, we do not see evidence of mathematical reasoning that is beyond the abilities of a typical 15 or 13 year old. However, both Johnny and Mikey took on quantitative tasks that are not required to sustain play of the game. For example, they figured out the optimal time to use a finishing move against three characters at one time. Mikey's calculation is not implied by the design of the game and certainly not necessary if the

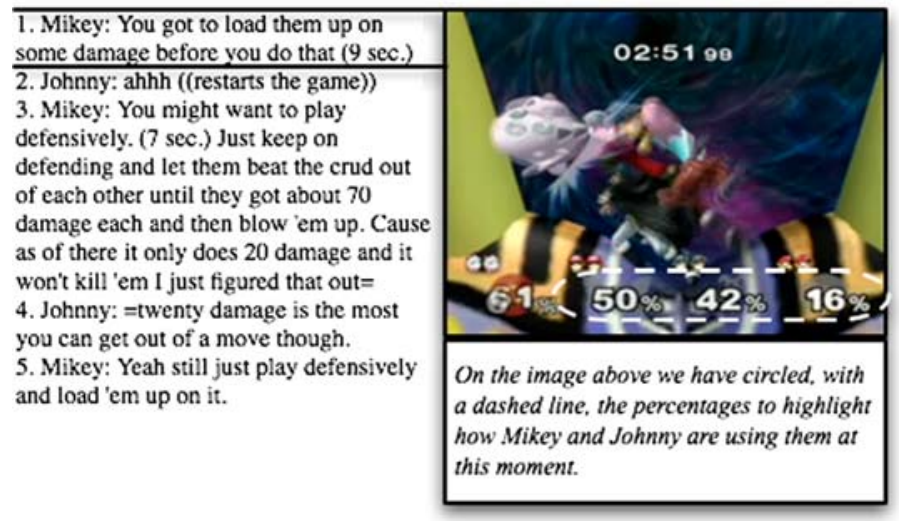

Fig. 5 Johnny and Mikey 2005-09-16_Tape1_00:15:55.26 


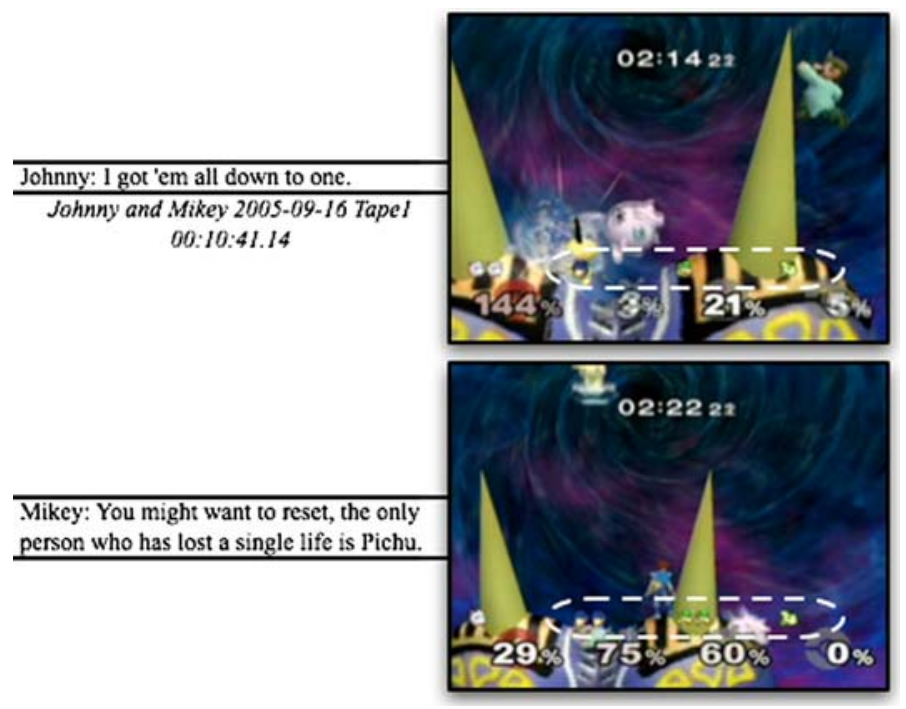

Fig. 6 Two statements and corresponding images where Johnny and Mikey use the life representations of separate characters as a combined set

player had already memorized a set of button combinations. Their coordination of the opponents' life is also not implicit in the design of the game; a player could use that particular character and attack his opponents one at a time. In attempting to complete the event they used some of the game's quantities to determine when to take a particular action and to assess whether or not it had worked.

\subsubsection{Quantitative Practice III: Coordinating and Projecting Future Quantitative States}

In the third section, we analyze a quantitative practice that involved coordinating disparate quantities in order to project future quantitative states to make actions based on those predictions. Figure 7 shows that of the 130 event attempts we recorded Johnny or Mikey used the restart command 75 times (58\%). How then did they know that a particular attempt would not be successful? Johnny and Mikey coordinated the game's quantitative representations on the screen including time, life, and an additional set of character icons. They coordinated these icons to determine if they were going to be successful at the task of defeating their opponents. They then made an immediate action, using the restart button, based on their prediction.

The transcript in Fig. 8 is from a moment leading up to Johnny's use of the restart command and demonstrates how time, life, and progress towards completing the task were coordinated. The lower image in Fig. 8 shows the screen just as Johnny reset and had indicated verbally that he would not be able to complete the level; "I'm not going to be able to do it" (Fig. 8, line 8). It is difficult to determine whether or not Johnny was correct in his assessment since he ended the event. However, when shown the same image and corresponding video during the artifact-based interview he made a similar prediction. Also, Johnny's statement is reasonable considering the limited time and number of characters he had to defeat. 


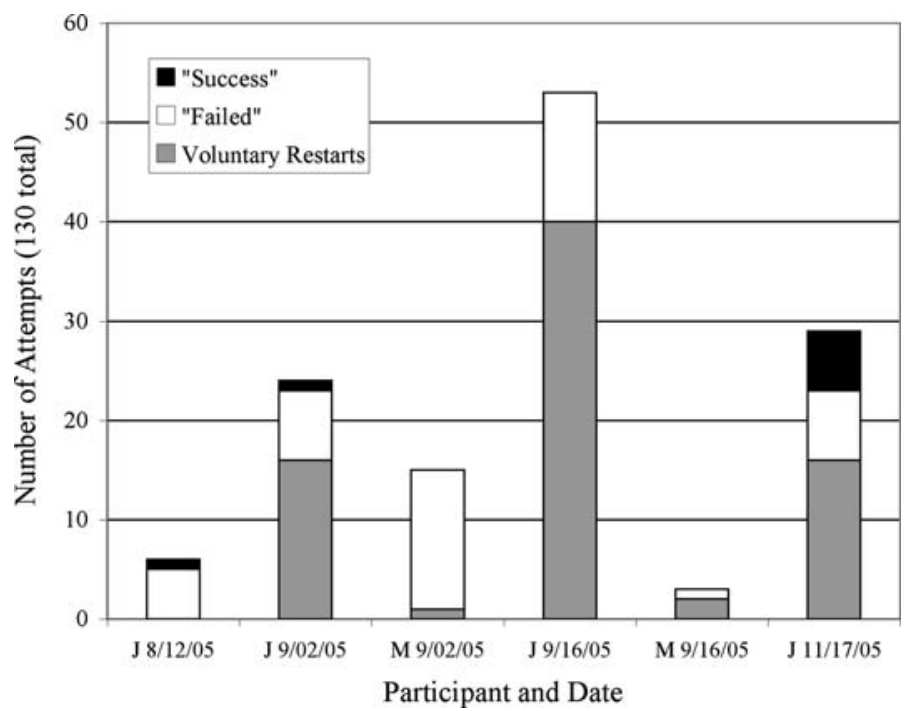

Fig. 7 A graph that shows the how the 130 attempts at various events ended. If the game flashed "failed" on the screen, then the event ended unsuccessfully. If the player was successful, "success" flashed on the screen. When neither "failed" nor "success" flashed on the screen, then the player had voluntarily ended the event using the restart command. The graph shows that voluntary restarts are a common part of their play. $M=$ Mikey and $J=$ Johnny

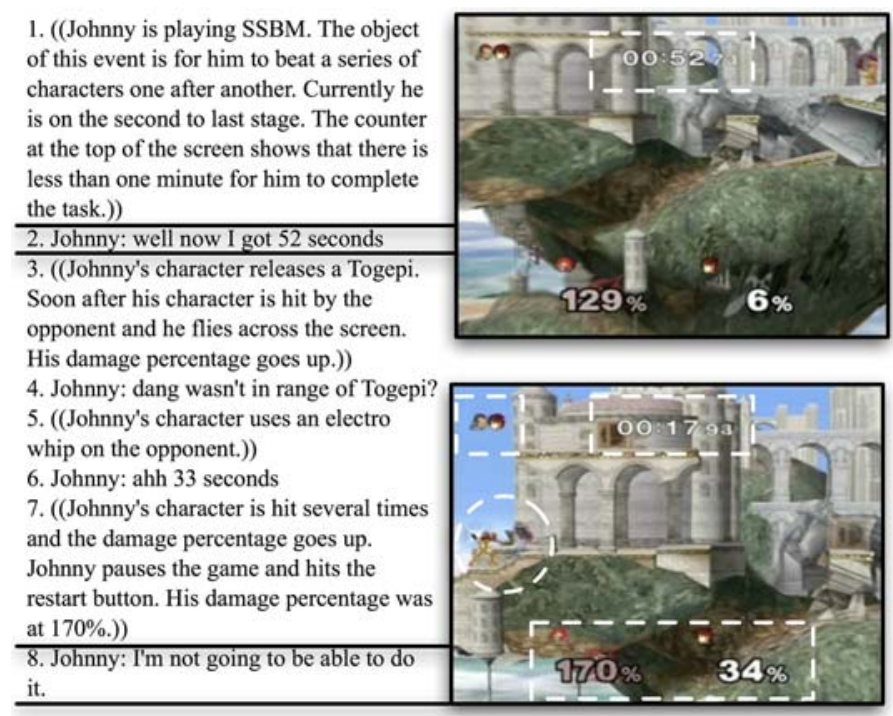

Fig. 8 Johnny and Mikey 2005 9-16 00:37:01.23. In the circle are the two characters that were battling; Johnny controlled one and the computer controlled the other. Inside the rectangles are the coordinated representations

The segment begins as Johnny referenced the amount of time he had left (line 2). He then went on to use two different moves to attack the computer character, the Togepi and the electro whip (lines 3-5). Johnny then again referenced the time left just prior to his 
already weakened character receiving more damage (lines 6 and 7). The segment ends as Johnny indicated that he was "not going be able to do it" (line 8). We believe that he was referring to the event's main task - defeating a series of characters one at a time before the timer at the top of the screen runs out. However, to know where he was with regard to completing the task, Johnny had to coordinate three disparate aspects of the screen: a set of icons in the top left corner that indicate the number of characters left to defeat, the timer, and the life representations at the bottom.

We began the analysis section with Mikey's statement that life representations can be used to determine "if you're gonna die" (see Transcript 1) and whether or not to surrender. His statement is remarkably descriptive of the restart pattern we find throughout the data set and demonstrate in Fig. 8, suggesting a particular kind of quantitative practice that involves coordinating various aspects of the screen as a means to know when to use the restart command. We also take this particular practice as an important element of how Johnny and Mikey improved their play of Melee.

Johnny and Mikey typically used the restart button when they were attempting a task they had not yet completed. Their use of the restart button recalls de la Rocha's (1986) "chronic snag" and Heath's (1991) "low-cost lessons." These two concepts help explain learning in the wake of an error or mistake. Specifically they highlight the utilization of social and material aspects of an environment to create solutions that result in changed practices. For de la Rocha, changing practice occurs when one encounters a chronic snag and utilizes existing contextual features of an environment to overcome the snag. In Heath's analysis of play in little league baseball she points out that mistakes are often used as opportunities for coaching to and learning by players as they verbally rethink and analyze how a situation might have otherwise played-out. Our observations indicated that video game play actively involves a similar kind of learning in both the design and the actual use of the restart button. In Transcript 3 Mikey and Johnny discussed the use of moves in Melee after Mikey unsuccessfully attempted to use Jigglypuff three times. The focus of their conversation was on whether Mikey used the "right moves" indicating that Johnny had monitored his brother's action and used his observations to provide some feedback.

\section{Transcript 3}

1. ((Mikey gets a "failure" after having restarted the battle the two previous

2. times. The game screen returns to the events menu. The same event is

3. selected; Johnny is now controlling the action on the screen.))

4. Mikey: It just doesn't work.

5. Johnny: That's because you weren't doing the right moves.

6. Mikey: Yeah I was $=$

7. Johnny: = Mikey you were only doing down B. She's got more moves than

8. down $\mathrm{B}$.

\section{[Johnny and Mikey 09-16-2005 00:06:26.14]}

Johnny and Mikey's coordination of the quantitative representations to decide when to restart can be further understood in Johnny's comments on Fig. 8 in a retrospective interview. We recorded his annotations with Video Traces, a piece of software that allows a user to record talk, gesture, and drawings over still and video images (see Fig. 9 and the appendix for interview procedure). In addition to his interpretation of the representations, Johnny related the characters' actions to the life representations using simple arithmetic: "he beats the heck out of Samus. And adds another .... fifty-five to my occurred damage 


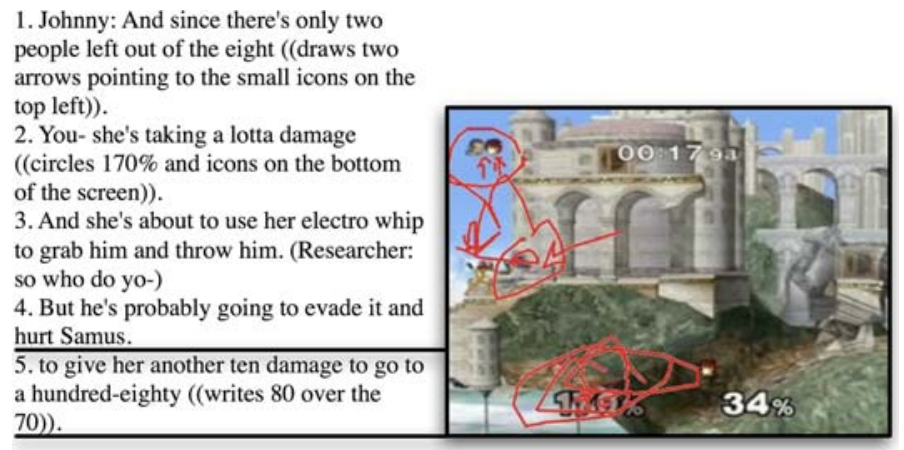

Fig. 9 Johnny and Mikey 2006-01-12 img1-1_00:00:28.16

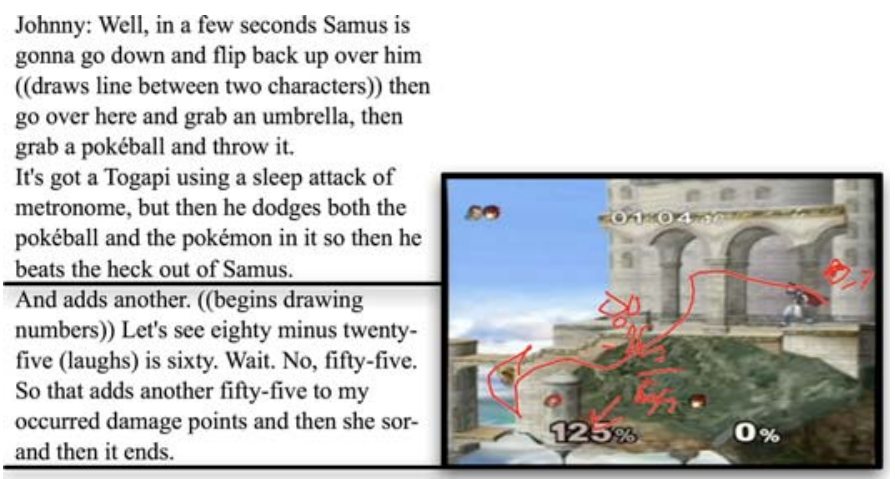

Fig. 10 Johnny and Mikey 2006-01-12 img1-2_00:00:14.07

points." Johnny also paused the video and wrote $80-25$ on the screen ${ }^{7}$ (see Fig. 10), a calculation that during play is done by the machine.

We have included this instance specifically to consider the relationship between quantities in games and formal educational contexts. The moment in Fig. 10 occurred when we, as researchers, disrupted the collection of devices and media that players use to complete tasks. The kinds of representations used in video games and school have a different set of embedded properties. To be successful at school math one needs to be able to create new representations in order to manipulate quantities; ${ }^{8}$ this is not the case in video games where players are mostly expected to interpret representations after a machine has completed the calculation. The quantitative practices we described above, and most of the ones we observed throughout our study, do not require the creation of new external representations or calculation. By adding an annotatable layer onto the video game and

\footnotetext{
${ }^{7}$ We interpret Johnny's calculation as his predicted outcome (180, from Fig. 9) minus the current status shown on the screen (125, from Fig. 10). Johnny had simplified the problem by excluding the hundreds place. This is a reasonable assumption given his ability to use the game's place value system and other representations from the game.

${ }^{8}$ To be clear, we are not suggesting that students must know how to "invent" new representations (c.f., diSessa et al. 1991). We are suggesting that students need to be able to reproduce existing representational forms as Johnny did in the interview.
} 
posing an elicitation problem (Stevens and Hall 1997), we inadvertently created a situation where the properties of two contexts (school and games) could align.

\subsection{Case Two: Vanessa and Final Fantasy X-2}

Our second case focuses on Vanessa's play of FF X-2 and her activities leading up to, during, and after the game's battles. Battles are a central component of the game because they are the mechanism that develops the characters' skills and allows them to achieve many of the game's major objectives. When a player fights in a battle she has a large permutation of moves and items available to her. As an example, the strategy guide that Vanessa purchased to go along with the game contains 347 pages (BradyGAMES 2004). It includes a variety of tables, charts, and diagrams that represent information on 251 enemies, 34 attack types, and 68 items along with quantitative descriptions of over 70 different ways to assign specific skills and abilities to the player's characters. The player's job is to match her opponents with an appropriate attack and character configuration. We know from studies of work and school settings that using representations, like those in the strategy guide and the game, requires disciplined perception (Lindwall and Lymer 2008; Stevens and Hall 1998). In the preceding case we described disciplined perception as it exists within the boundary of a battle of a particular game. In this case, we expand beyond the boundary of a battle to further understand how quantities are used to predict future quantitative states in video games. We have organized the three sections of this case to answer the following questions:

How does the player prepare for inevitable battles?

How does the player determine what to do in a battle?

How does the player recover from a battle?

\subsubsection{Quantitative Practice IV: Using and Organizing Quantitative Resources to Prepare for Future Activity}

This section shows Vanessa's use and organization of quantitative resources prior to attacking her opponents. Vanessa claimed to have thought about her opponents "logically" and sought out information on them in the strategy guide. We also see that the problems she faced in the game permeate other aspects of her life (i.e. school) where she maintained a set of external resources including her strategy guide and a notebook.

Figure 11 is an example of Vanessa's thought process as she encountered an opponent that had beaten her on a prior occasion. She recalled the avatar's appearance (i.e., fire; Fig. 11, line 4) and assumed this was his weakness. She planned to match his weakness with a specific category of attacks (i.e., water). In other words, Vanessa made a prediction of how well a particular move would work then put the prediction into action. This prediction-action sequence is based on quantitative information: the relative weakness of an opponent in comparison to the strength of a specific kind of attack. However, the quantities do not appear to be represented numerically, rather they appear as a part of the graphical representation of a character.

The instance in Fig. 11 also shows that Vanessa retained a focus on the avatar's appearance throughout the battle. After fighting the enemy for several minutes Vanessa correctly predicted that the enemy was almost "done." When asked further, rather than point to the numerical information that had just appeared on the screen, Vanessa directed the researcher to the appearance of her opponent's avatar (Fig. 11, line 11). She confirmed 
1. ((Vanessa's characters run down a hallway towards an enemy "boss.")) 2. Vanessa: Although this shouldn't take long 'cause I can use one thing for this one.

3. Researcher: You've fought this one before?

4. Vanessa: Yeah well when I first fought it I didn't know what to do and now I thought well, logically fire vs. water. Duh. 5. Researcher: (in audible) 6. Vanessa: Yeah I just keep hitting it with water.

7. ((Several minutes have pass in the battle. Vanessa selected the move Ma'at's Feather which allows her to view information about the enemy.)) 8. Vanessa: He's almost done.

9. ((Information view disappears, screen returns to regular battle view.)) 10. Researcher: How do you know? 11. Vanessa: Can't you see him limpin'?
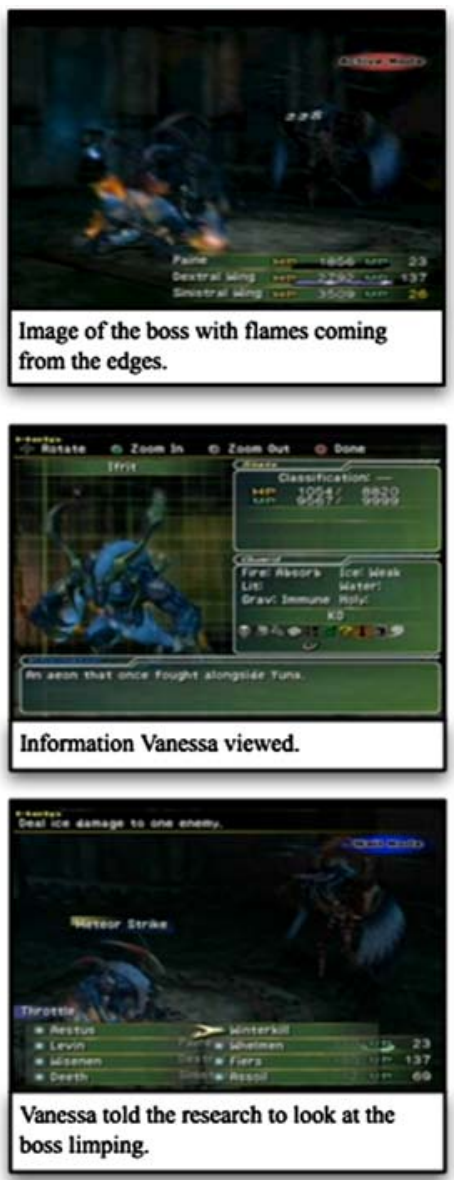

Fig. 11 Vanessa 2006-01-19_00:35:25.28

this interpretation of the enemy's avatar when she annotated a video of the battle. Vanessa used the avatar's appearance as a resource for quantitative information, specifically to ascertain a reading of its HP.

The instance in Fig. 11 shows Vanessa's use of graphical resources. However, it leaves open the question of how Vanessa used the information in the strategy guide that she purchased because of difficulty of her opponents (see Transcript 4 lines 4-5). Vanessa had encountered a problematic enemy that appeared as a gel (see Transcript 4 lines 6-8) and learned from the strategy guide the color of the gel was an indication of its weakness (see Transcript 4 lines 10-11). She then used this information to pair attacks against the enemy's weakness (see Transcript 4 lines 11-14).

\section{Transcript 4}

1. If it's hard or it's sometimes a fiend may oversoul, which means it

2. gains stronger powers and stuff you know. HP becomes larger and

3. becomes harder to defeat. And so I take for the ability to do that I

4. would have to figure out, one, its weaknesses. That's why I got the 
5. strategy guide to um figure out all its weaknesses. Cause its really

6. hard to tell. As I know I had this um, it looked like a large gel, this

7. one char- this one fiend (Researcher: uhh). And so that was really

8. hard to defeat too because each time I tried to use an element it

9. would absorb it or it wouldn't work, so I had to figure out. And the

10. ga- the strategy guide said to either look at the colors, cause it

11. would change colors and so I would use certain elem- the opposite

12. of that element. It's like if it was red I would have to use ice to cool

13. it down (Researcher: hmm). That means it was- it would absorb

14. fire because you can tell.

\section{[Vanessa 2006-02-16 exit-interview-tape2 00:04:43.1]}

Vanessa thought about and considered her opponents on quantitative terms while she was not fighting against them and not playing the game. When she did play the game she had the strategy guide next to her as we might expect. However, she also read and took notes from it into a special notebook during breaks at school. In some ways, Vanessa was not only a player of FF X-2 but also a student. As problems emerged within the game, she used an external resource to identify a solution. The solutions were built into simple quantitative pairings that categorized particular strengths against weaknesses.

\subsubsection{Quantitative Practice V: Saving Effort}

This next section shows how Vanessa selected specific moves within battles to make them quicker and easier. At times Vanessa altered her characters' strengths and available moves while she was in the midst of a battle. She made the alteration by changing a character's dressphere, the means by which a character's role in the battle is assigned. ${ }^{9}$ For the most difficult enemies, Vanessa used something called a special dressphere. Using a special dressphere took several moves, which opened her characters to enemy attacks. However a special dressphere also gave her characters more strength, HP, and attack options. Vanessa explained to us that a special dressphere is something "that gains more power" and that she was able to use when her characters were nearly defeated (Vanessa 2006-02-16_img14-1). She also used dresspheres to lessen the time that a battle would take her.

Vanessa viewed the use of special dresspheres on quantitative terms and as a functional means to match her characters with the enemies. In the short segment below Vanessa described how using a special dressphere was one way that she raised her characters' strengths and HP to match the more powerful enemies (see Transcript 5 turns 13-16). Her basis for making the decision on whether to use the dressphere was her perception of how long the battle would take (see Transcript 5 turns 1-2). Though she clearly came out in favor of using special dresspheres, she viewed them as an option and indicted that she was able to fight without them (Transcript 5 lines 2-4). Vanessa then is basing her actions in the game on quantitative information.

\section{Transcript 5}

1. Vanessa: So each time like- if it takes a long- if I know its gonna take a

\footnotetext{
${ }^{9}$ For example, some dresspheres are specifically designed to allow a character to raise the HP of the other two characters. Other dresspheres, like "warrior", are used if the player wants the character to attack the enemy.
} 
2. long time I usually just put on a special dressphere and just use that

3. instead. Instead of just doing all three of em (Researcher: mhhm) I just use

4. a special dressphere so it'll be quicker.

5. Researcher: So your just one person then?

6. Vanessa: Yeah. Use one person only.

7. Researcher: Does that work out for you?

8. Vanessa: Yeah. Actually it does. If- uh longer battles any uh bigger fiends

9. with bigger um more power. More powerful attacks. Like aeons, I

10. definitely use special dresspheres on aeons. Cause either I die or it takes

11. too long.

12. Researcher: So why do you think it works better?

13. Vanessa: Well I think it's cause, well, since the fiends- it's like the aeons

14. and the fiends both have, you know, have stronger powers and if you use-

15. it's like the same thing as if they had special dresspheres since I have

16. special dresspheres they have special powers.

[Vanessa 2005-10-13_00:13:15.09]

We liken Vanessa's use of dresspheres to Scribner's (1997) notion of effort saving practices where solutions to problems vary based on what will require the least effort. However, rather than avoid physical or mental effort Vanessa looked to save time. She perceived time as a quantity that she could adjust by increasing her character's strength, thereby making the game easier. Vanessa used the enemy's HP as a proxy for the length of a battle, and then altered her characters to match the opponent and shorten the length of a battle.

Because the enemy's weakness is only one portion of the overall equation that determines the winner of a battle, Vanessa utilized other quantities as well. Specifically, she attended to a numerical representation of her own characters' health. The value of this representation to Vanessa's play was apparent in battles where she struggled to beat the enemy. An example of this kind of breakdown appears in the segment below where Vanessa changed moves as her characters' HP decreased (see Fig. 12). Unlike the enemy's HP her characters' HP are represented in a precise numerical format at all times during a battle. In the previous section Vanessa's moves were based on her prediction of how the enemy would react to them. In this instance we see her moves determined by the changing quantitative conditions in the battle, which are represented in the character's avatars and the numeric information.

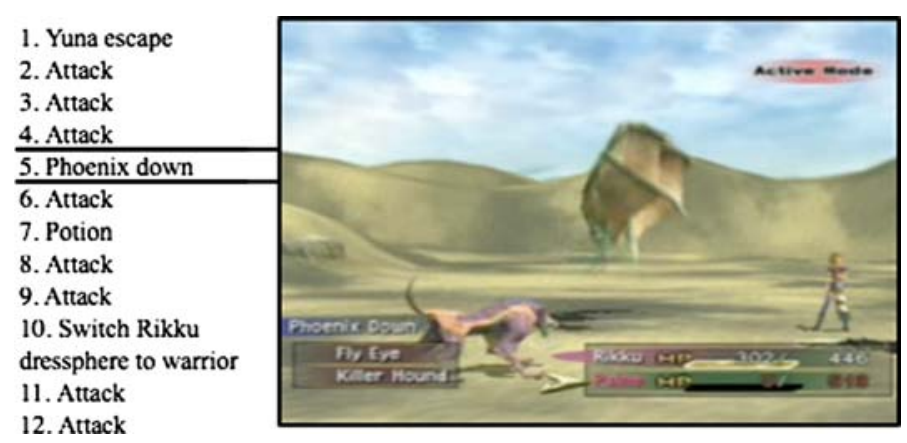

Fig. 12 Vanessa 2005-08-25_00:46:10. A sequence of moves made by Vanessa during a battle. Vanessa attacked until her character's HP reached 0 as indicated in the table on the right side of image 


\subsubsection{Quantitative Practice VI: Stocking and Using Potion}

This section describes how Mikey and Vanessa referred to the number of potions, the strength of characters, and the amount of money held by the characters to support contrasting views on whether Vanessa would be successful in two different games. Vanessa often restored her characters' lost HP after battles in two games, Kingdom Hearts and FF X-2, by giving them potion she had purchased or gained from defeating her opponents. In Transcript 6 Vanessa commented on a sequence of her play in Kingdom Hearts. In the sequence Vanessa recognized how her character's actions impacted the amount of money and potions she held and prepared her for the future task of defeating a "boss". 10

\section{Transcript 6}

1. Vanessa: I was collecting money and stuff. And defeating heartless so I

2. can gain money and I can go back to the item shop, to collect um some

3. potions and buy some potions then go for, I'm not sure for which part, of

4. the game, where I was. I think I was at the beginning. I'm sure I was at the

5. beginning. I'd collect so I can defeat this one boss.

[Vanessa 2006-02-16_img5-2]

Vanessa also commented on a sequence of her play from FF X-2. Her reaction to this sequence was similar to the previous one in that she once again focused on the number of potions her characters had. However, in the FF X-2 sequence she used the number of potions as evidence that she was successful (see Transcript 7).

\section{Transcript 7}

1. Researcher: So is there anything on this screen that tells you whether or

2. $\operatorname{not}=$

3. Vanessa: $=$ um

4. Researcher: $=$ how you'll do?

5. Vanessa: Cause I can tell, I know I had a lot of items um.

6. ((Vanessa adjusts the video segment to a point where her characters' items

7. are on the screen then circles a listing of potions and other items.))

8. Vanessa: And this part, I had, I know I didn't have a lot of potions but they

9. were useful, for when I needed it. And I was able to always just in case I

10. needed potion I always had it. Or if I use some of it or just use most of it.

11. And I think the reason why I was successful on this part was because,

12. anyway I had a lot of potions and I was able to get through it.

\section{[Vanessa 2006-02-16_img7-2]}

Vanessa's potion stocking and use after battles is a quantitative practice. She was using a subset of the many quantities present in these games (potions, money, and HP) to determine her actions. To demonstrate an alternative practice we turn to Mikey's comments on the same set of game sequences we presented above. Mikey and Johnny also played Kingdom Hearts and other role-playing games similar to FF X-2. In their response to the Kingdom Hearts video, Mikey did most of the commenting. However, Johnny noticed that

$\overline{10}$ Vanessa uses the terms 'fiend', 'aeon', or 'boss' in reference to specific kinds of enemies. 
she had sold an important item in the game to purchase the potions. Mikey then cited this as evidence that she would not be successful (see Transcript 8). ${ }^{11}$

\section{Transcript 8}

1. Mikey: Right now he's buying some stuff to recover health and things like

2. that and um

3. ((Mikey turns his head to read a question from the sheet of paper in front

4. of him.))

5. Mikey: who's going to be successful

6. Johnny: He's selling his Brave Warrior Wristband?

7. Mikey: So he's not going to be successful because he just sold a very very

8. important item.

9. Researcher: What's that?

10. Johnny: For a potion

11. Mikey: A Brave Warrior, it's a wristband that makes you stronger and its

12. useful in the beginning of the game where this guy is. So he's got money

13. now but it's really not all that great 'cause he's just sold one of his most

14. important things.

\section{[Johnny and Mikey 2006-01-12_img5-3]}

Mikey's claim was that the sale of the wristband was not worth the money gained from it, even if used to purchase potions, because it weakened Vanessa's character. Mikey then is placing a higher relative value on the strength of the character over the number of potions and amount money held by a character. In the FF X-2 sequence he made a similar critique, but this time focused on Vanessa's use of potion to heal her characters (see Transcript 9).

\section{Transcript 9}

1. Mikey: Right now they're healing all their people, that's a bad way to heal

2. 'em though just using up potions. They should just use their magic so they

3. don't use up all their potions in case their magic user dies.

\section{[Johnny and Mikey 2006-01-12_img7-2]}

Mikey suggested that Vanessa's reliance on potion to regularly heal her characters ultimately left her worse off in the game. He does offer using magic as an alternative means of repairing her characters' HP. However, Mikey's suggestion is based in an assumption that one of Vanessa's characters is a magic user, an option that she chose not to take at that particular point in the game. Mikey's alternative could be, if put into action, another quantitative practice because he assigned a different value to the characters' strength and healing abilities than Vanessa. It seems as though Mikey tended to favor having a magic user, which will result in fewer attackers but make him less reliant on potions. In his view the difference is significant to the game's final outcome. Though Vanessa did not have an opportunity to respond to Mikey's critique, the end of her comment on the FF X-2 sequence provides additional justification for using potions to regularly heal characters; potions are commonly given out for free after battles (see Transcript 10).

\footnotetext{
11 Although Vanessa and Mikey lived in the same city only a few miles apart to our knowledge they did not know each other at the time of our study. Also, we did not tell the participants who was playing the game in the videos they were watching. For this reason Mikey and Johnny use a male pronoun to refer to the person playing the game.
} 


\section{Transcript 10}

1. Vanessa: I think I didn't go broke because each time I defeated a fiend

2. they always gave me a potion or a hi-potion.

3. Researcher: So that made up for the ones that you used?

4. Vanessa: Yeah, they always did, they always gave you like- they had to

5. give you something.

6. Researcher: uhun

7. Vanessa: Whether it was a antidote or a echo screen or something like that.

\section{[Vanessa 2006-02-16_img7-2]}

The difference in Mikey and Vanessa's approach is in how they chose to manage quantitative aspects of the resources provided by the game. Vanessa favored keeping a large number of potions and assigning all of her characters as attackers. Mikey preferred to spend less money on potion, instead to use other items and repair HP by assigning one of his characters to the role of a magic user. Mikey and Vanessa referred to quantities such as strength of characters, the cost of potion, money, and the number of potion as evidence of whether a particular strategy would work.

\section{Discussion}

To begin the final section of this paper we return to our underlying question; how do we come to understand young people's uses of quantity in video games? To quote Nespor (1997) we have attempted to look at "kids as the central participants, exchanging, invoking, inhabiting, and appropriating adult-produced representations that circulate through the spaces of popular culture" (p. 174, italics in original). What we have found is that young people's use of these representations is intentional and goal-directed. For us further understanding the systematic use of representations in game play will help solidify the space upon which we think about the competencies young people enter school with and contexts they encounter immediately following the school day.

The cases we presented above illustrate an essential aspect of finding and understanding young people's experiences with quantity outside of school; namely that our participants rarely did math in a conventional sense. Instead we witnessed distributed sets of practices, where young people interpret and use representations and machines conduct essential computational work. While the embedded computational complexity of commercial games has dramatically increased over time (c.f., Gee 2003; Johnson 2005), our analysis demonstrates that machines have taken over quantitative tasks that at one time were left to the player. Our participants did not calculate scores, keep tables, or determine how to allocate winnings as they might have done had we observed them playing non-digital games (Griffin et al. 1994; Guberman and Saxe 2000; Heath 1991; Nasir 2005; Saxe and Bermudez 1996). They did, however, use the represented quantities to make predictions about future states of the game and to determine their actions.

Our findings also highlight several aspects of game play that are informative for how quantitative practices are learned. On the one hand, games are open-ended and allow for multiple ways of achieving success. On the other hand, open-ended games often come with well-defined tasks and explicit markers of achievement. This balance allows for the emergence of many different kinds of goal-directed quantitative practices. We saw this in 
the final quantitative practice where Mikey and Vanessa expressed different approaches to the game based on the number of potions, character strength, and amount of money.

Mikey and Vanessa's use of quantities as evidence raises the question of how to use similar kinds of segments to spark debates amongst young people in formal educational settings. These debates, ideally would lead to more advanced quantitative reasoning that analyzes the tradeoffs of using particular sets of resources. Students would be asked to mathematically consider how the multiple variables they encounter in games (i.e., potion, strength, life, etc.) could be used to predict the outcomes of particular actions. Argumentation has been used quite successfully as a pedagogical technique in a variety of disciplines (Bell 2002; Stevens et al. 2005). Additionally, some researchers have shown the presentation of evidence as an important aspect to argumentation in video game web forums (Steinkuehler and Duncan 2008, in press). What we do not know much about is what argumentation around video games would look like in the context of school.

The difference of opinion expressed by Mikey and Vanessa in the final analysis section gives us some indication of a possible model for using video games as the basis of argumentation. First, it may be possible with existing video games that young people already play in great numbers. Second, long periods of play are not necessary in the academic setting. The data above shows that young people are able to interpret short oneminute clips and still images. A rather simple pattern in Vanessa's play was not only detectable in a short video segment by our participants but also provided enough information for a difference of opinion to emerge. This addresses one of the most problematic aspects of bringing existing video games in educational settings, they take a long time to play. Finally, it may be possible to provoke differences of opinion by asking basic questions about efficiency, tactics, strategies, and success.

A significant aspect of whether this model could be successful is knowing how to bring more complex quantitative reasoning to the topic. However, the field already has a great deal of expertise in doing this so we speculate that it is a problem that can be addressed. Additionally, games as a topic of inquiry in school lacks the social importance that is typical of many argument-based inquiry projects. Conversely, important mathematical topics like rate of change and proportion are the basis of how many games function.

In our observations we did not see any official assessment or critique of a player's method, we only witnessed markers of their accomplishments (e.g., levels passed, points earned, etc.). If we had been observing quantitative practices in school we likely would have seen our participants having to "explain their thinking" or show their work on paper (Stevens 2000b). The implication of not having to inscribe an interpretation on paper for public examination is that players are less committed to particular meanings and are provided room to shift their understanding. This is not to say that all interpretations in game play remain private, recall that Johnny and Mikey openly discussed strategies, however there was not an official enduring external assessment of ideas that could be invoked at a later date as evidence of their competencies. While we do not think teachers should abandon having students write their ideas down, we do think this aspect of games is an important part of how young people learn to play.

Ultimately, we have added the adaptive use of quantitative representations to our field's understanding of how young people emergently organize learning in and around video games. In other words, in this particular context young people are not just learning to use quantitative representations but using quantitative representations to learn. In both cases we presented here the players used quantitative representations in order to advance their own play. While their uses are seemingly different from formalized STEM practices, we contend they are not entirely unrelated. 
Acknowledgements We would like to thank Laurie McCarthy for her assistance on this research, the editor Bruce Sherin, and two anonymous reviewers for their comments on an earlier draft of this paper. This work was supported by a grant from the National Science Foundation (NSF\#0354453). Any opinions, findings and conclusions expressed here are those of the authors and do not necessarily reflect the views of the National Science Foundation.

\section{Appendix}

Each participant was asked to annotate a set of eight images as well as one minute of corresponding video using Video Traces. We collected the images and video during field visits and selected them specifically for each participant. Most of the images and videos came from games the participant had played during our observations, however we also included two additional games he or she had not played. We began with a ten-minute overview of how to use Video Traces.

Before annotating each image or video we asked the participant:

(1) Do you know what game it is?

(2) What do you think was happening in the game when this was taken? How do you know?

(3) Tell me how you would figure out who is going to be successful.

We also provided them with the following written directions:

Take about one minute.

Talk about whatever you like, but try to answer the following questions.

\#1. What game?

\#2. What is going on in the game?

\#3. How would you figure out who is going to be successful?

\section{References}

Barab, S., Sadler, T., Heiselt, C., Hickey, D., \& Zuiker, S. (2007). Relating narrative, inquiry, and inscriptions: Supporting consequential play. Journal of Science Education and Technology, 16(1), 5982. doi:10.1007/s10956-006-9033-3.

Barab, S., Thomas, M., Dodge, T., Carteaux, R., \& Tuzun, H. (2005). Making learning fun: Quest Atlantis, a game without guns. Educational Technology Research \& Development, 53(1), 86-107. doi:10.1007/ BF02504859.

Bateson, G. (1972). Form, substance, and difference. In Steps to an ecology of mind (pp. 448-466). New York: Ballantine Books.

Beach, K. (1995). Activity as a mediator of sociocultural change and individual development: The case of school-work transition in Nepal. Mind, Culture, and Activity, 2(4), 285-302.

Becker, H. S. (1982). Art worlds. Berkeley, CA: University of California Press.

Bell, P. (2002). Using argument map representations to make thinking visible for individuals and groups. In T. Koschmann, R. Hall \& N. Miyake (Eds.), CSCL 2: Carrying forward the conversation (pp. 449485). Mahway, NJ: Lawrence Erlbaum Associates.

BradyGAMES. (2004). Final Fantasy X-2: Official strategy guide. Indianapolis, IN: BradyGAMES Publishing.

Bransford, J. D., Brown, A. L., \& Cocking, R. R. (Eds.). (2000). How people learn: Brain, mind, experience, and school. Washington, D.C.: National Academy Press.

Bransford, J. D., \& Schwartz, D. L. (1999). Rethinking transfer: A simple proposal with multiple implications. In A. Iran-Nejad \& P. D. Pearson (Eds.), Review of research in education (Vol. 24, pp. 61100). Washington, DC: AERA.

Bransford, J. D., Vye, N., Stevens, R., Kuhl, P., Schwartz, D., \& Bell, P. (2006). Learning theories and education: Toward a decade of synergy. In P. Alexander, P. Winne, et al. (Eds.), Handbook of educational psychology (2nd ed., pp. 209-244). Mahwah, NJ: Erlbaum. 
Cobb, P., Yackel, E., \& Wood, T. (1992). A constructivist alternative to the representational view of mind in mathematics education. Journal for Research in Mathematics Education, 23(1), 2-33. doi:10.2307/ 749161.

de la Rocha, O. L. (1986). Problems of sense and problems of scale: An ethnographic study of arithmetic in everyday life. Unpublished Dissertation, University of California, Irvine.

diSessa, A., Hammer, D., Sherin, B., \& Kolpakowski, T. (1991). Inventing graphing: Meta-representational expertise in children. Journal of Mathematical Behavior, 10, 117-160.

diSessa, A., \& Sherin, B. (2000). Meta-representation: An introduction. Journal of Mathematical Behavior, 19, 385-398.

Enyedy, N. (2005). Inventing mapping: Creating cultural forms to solve collective problems. Cognition and Instruction, 23(4), 427-466.

Gee, J. P. (2003). What video games have to teach us about learning and literacy. New York: Palgrave.

Goodwin, C., \& Goodwin, M. H. (1998). Seeing as a situated activity: Formulating planes. In Y. Engestrom \& D. Middleton (Eds.), Cognition and communication at work (pp. 61-95). Cambridge, UK: Cambridge University Press.

Greenfield, P. M. (1994). Video games as cultural artifacts. Journal of Applied Developmental Psychology, 15, 3-12.

Greenfield, P. M., Camaioni, L., Ercolani, P., Weiss, L., Lauber, B. A., \& Perucchini, P. (1994). Cognitive socialization by computer games in two cultures: Inductive discovery of mastery of an iconic code? Journal of Applied Developmental Psychology, 15, 59-85.

Griffin, S. A., Case, R., \& Siegler, R. (1994). Rightstart: Providing the central conceptual prerequisites for first formal learning of arithmetic to students at risk for school failure. In K. McGilly (Ed.), Classroom lessons: Integrating cognitive theory and classroom practice (pp. 25-49). Cambridge, MA: The MIT Press.

Guberman, S. R., \& Saxe, G. B. (2000). Mathematical problems and goals in children's play of an educational game. Mind, Culture, and Activity, 7(3), 201-216.

Hall, R., Lehrer, R., Lucas, D., \& Schauble, L. (2004). Of grids and jars: A comparative analysis of representational infrastructure and learning opportunities in middle school and professional science. In Y. B. Kafai, W. A. Sandoval, N. Enyedy, A. S. Nixon \& F. Herrera (Eds.), Embracing diversity in the learning sciences: Proceedings of the Sixth International Conference of the Learning Sciences (pp. 238-245). Mahwah, NJ: Lawrence Erlbaum Associates.

Hall, R., Stevens, R., \& Torralba, A. (2002). Disrupting representational infrastructure in conversations across disciplines. Mind, Culture, and Activity, 9(3), 179-210.

Harper, D. (1997). Working knowledge: Skill and community in a small shop. Chicago: University of Chicago Press.

Heath, S. B. (1991). "It's about winning!” The language and knowledge of baseball. In L. B. Resnick, J. M. Levine \& S. D. Teasley (Eds.), Perspectives in socially shared cognition (pp. 101-124). Washington, D.C.: American Psychological Association.

Hutchins, E. (1995a). Cognition in the wild. Cambridge, MA: MIT Press.

Hutchins, E. (1995b). How a cockpit remembers its speeds. Cognitive Science, 19, 265-288.

Ito, M. (2008). Education vs. entertainment: A cultural history of children's software. In K. Salen (Ed.), The ecology of games: Connecting youth, games, and learning (pp. 89-116). Cambridge, MA: The MIT Press.

Izsák, A. (2004). Students' coordination of knowledge when learning to model physical situations. Cognition and Instruction, 22(1), 81-128.

Izsák, A. (2005). 'You have to count the squares': Applying knowledge in pieces to learning rectangular area. Journal of the Learning Sciences, 14(3), 361-403.

Johnson, S. (2005). Everything bad is good for you: How today's popular culture is actually making us smarter. New York: Riverhead Books.

Jordan, B., \& Henderson, A. (1995). Interaction analysis: Foundations and practice. Journal of the Learning Sciences, 4(1), 39-103.

Kafai, Y. B., Franke, M., Ching, C., \& Shih, J. (1998). Game design as an interactive learning environment fostering students' and teachers' mathematical inquiry. International Journal of Computers for Mathematical Learning, 3(2), 149-184.

Kaput, J. J. (1998). Representations, inscriptions, descriptions and learning: A kaleidoscope of windows. Journal of Mathematical Behavior, 17(2), 265-281.

Latour, B. (1992). Where are the missing masses? The sociology of a few mundane artifacts. In W. E. Bijker \& J. Law (Eds.), Shaping technology/building society (pp. 225-258). Cambridge, MA: MIT Press.

Latour, B. (1996). On interobjectivity. Mind, Culture, and Activity, 3(4), 228-245.

Lave, J. (1988). Cognition in practice: Mind, mathematics and culture in everyday life. Cambridge, UK: Cambridge University Press. 
Lave, J., \& Wenger, E. (1991). Situated learning: Legitimate peripheral participation. Cambridge: Cambridge University Press.

Lehrer, R., Strom, D., \& Confrey, J. (2002). Grounding metaphors and inscriptional resonance: Children's emerging understanding of mathematical similarity. Cognition and Instruction, 20(3), 359-398.

Leinhardt, G., Zaslavsky, O., \& Stein, M. K. (1990). Functions, graphs, and graphing: Tasks, learning, and teaching. Review of Educational Research, 60(1), 1-64.

Lenhart, A., Kahne, J., Middaugh, E., Macgill, A. R., Evans, C., \& Vita, J. (2008). Teens, video games, and civics: Teens' gaming experiences are diverse and include significant social interaction and civic engagement. Washington, D.C.: Pew Internet \& American Life Project.

Lindwall, O., \& Lymer, G. (2008). The dark matter of lab work: Illuminating the negotiation of disciplined perception in mechanics. The Journal of the Learning Sciences, 17, 180-224.

List of best-selling video games. (2007). In Wikipedia, The Free Encyclopedia. Retrieved 18:11, November 5, 2007, from http://en.wikipedia.org/w/index.php?title=List_of_best-selling_video_games\&oldid= 169314438.

Lowrie, T. (2005). Problem solving in technology rich contexts: Mathematics sense making in out-of-school environments. Journal of Mathematical Behavior, 24, 275-286.

Nasir, N. (2005). Individual cognitive structuring and the sociocultural context: Strategy shifts in the game of dominoes. The Journal of the Learning Sciences, 14(1), 5-34.

Nelson, B. C. (2007). Exploring the use of individualized, reflective, guidance in an educational multi-user virtual environment. Journal of Science Education and Technology, 16(1), 83-97.

Nespor, J. (1997). Tangled up in school: Politics, space, bodies, and signs in the educational process (sociocultural, political, and historical studies in education). Hillsdale, NJ: Lawrence Erlbaum Associates.

Ochs, E., Taylor, C., Rudolph, D., \& Smith, R. (1992). Storytelling as a theory-building activity. Discourse Processes, 15(1), 37-72.

Palinscar, A. S. (1989). Less charted waters. Educational Researcher, 18, 5-7.

Rieber, L. P. (1996). Seriously considering play: Designing interactive learning environments based on the blending of microworlds, simulations, and games. Educational Technology Research \& Development, 44(2), 43-58.

Rose, M. (2004). The mind at work: Valuing the intelligence of the American worker. New York: Viking.

Salen, K., \& Zimmerman, E. (2004). Rules of play: Game design fundamentals. Cambridge, MA: The MIT Press.

Satwicz, T., \& Stevens, R. (2008). People, technology, and learning: A distributed perspective on collaborative activity. In J. M. Spector, M. D. Merrill, J. J. G. v. Merriënboer \& M. P. Driscoll (Eds.), Handbook of research on educational communications and technology (pp. 163-171). Mahwah, NJ: Lawrence Erlbaum Associates.

Saxe, G. B. (1991). Culture and cognitive development: Studies in mathematical understanding. Hillsdale, NJ: Lawrence Erlbaum Associates.

Saxe, G. B., \& Bermudez, T. (1996). Emergent mathematical environments in children's games. In L. P. Steffe \& P. Nesher (Eds.), Theories of mathematical learning (pp. 51-68). Mahwah, NJ: Lawrence Erlbaum Associates.

Schwartz, D., Bransford, J., \& Sears, D. (2005). Efficiency and innovation in transfer. In J. Mestre (Ed.), Transfer of learning: Research and perspectives (pp. 1-51). Greenwich, CT: Information Age Publishing.

Scribner, S. (1997). Studying working intelligence. In E. Tobach, R. J. Falmagne, M. B. Parlee, L. M. W. Martin \& A. S. Kapelman (Eds.), Mind and social practice: Selected writings of Sylvia Scribner (pp. 338-366). Cambridge: Cambridge University Press.

Squire, K. (2006). From content to context: Videogames as designed experience. Educational Researcher, 35(8), 19-29.

Squire, K., Barnett, M., Grant, J. M., \& Higginbotham, T. (2004). Electromagnetism supercharged! Learning physics with digital simulation games. In Y. B. Kafai, W. A. Sandoval, N. Enyedy, A. S. Nixon, \& F. Herrera (Eds.), Embracing diversity in the learning sciences: Proceedings of the Sixth International Conference of the Learning Sciences (pp. 513-520). Mahwah, NJ: Lawrence Erlbaum Associates.

Squire, K., \& Klopfer, E. (2007). Augmented reality simulations on handheld computers. The Journal of the Learning Sciences, 16(3), 371-413.

Squire, K. D., \& Jan, M. (2007). Mad City Mystery: Developing scientific argumentation skills with a placebased augmented reality game on handheld computers. Journal of Science Education and Technology, $16(1), 5-29$.

Steinkuehler, C., \& Duncan, S. (2008). Scientific habits of mind in virtual worlds. Journal of Science Education and Technology. doi:10.1007/s10956-008-9120-8. 
Stevens, R. (1999). Disciplined perception: Comparing the development of embodied mathematical practices at work and school. Unpublished Dissertation, University of California Berkeley, Berkeley, CA.

Stevens, R. (2000a). Divisions of labor in school and in the workplace: Comparing computer and papersupported activities across settings. The Journal of the Learning Sciences, 9(4), 373-401.

Stevens, R. (2000b). Who counts what as math: Emergent and assigned mathematical problems in a projectbased classroom. In J. Boaler (Ed.), Multiple perspectives on Mathematics Education (pp. 105-144). New York: Elsevier.

Stevens, R. (2007). Capturing ideas in digital things: A new twist on the old problem of inert knowledge. In R. Goldman, R. Pea, B. Barron \& S. Derry (Eds.), Video research in the learning sciences (pp. 565578). Mahwah, NJ: Lawrence Erlbaum \& Associates.

Stevens, R., \& Hall, R. (1997). Seeing tornado: How video traces mediate visitor understandings of (natural?) spectacles in a science museum. Science Education, 18(6), 735-748.

Stevens, R., \& Hall, R. (1998). Disciplined perception: Learning to see in technoscience. In M. Lampert \& M. L. Blunk (Eds.), Talking mathematics in school: Studies of teaching and learning (pp. 107-149). Cambridge: Cambridge University Press.

Stevens, R., Mertl, V., Levias, S., \& McCarthy, L. (2006). Money matters: The social and material organization of consequential financial practices in families. In S. Barab, K. E. Hay, \& D. T. Hickey (Eds.), Proceedings of ICLS 2006 (Vol. 2, pp. 1088-1093). Mahwah, NJ: Lawrence Erlbaum Associates and International Society of the Learning Sciences.

Stevens, R., Satwicz, T., \& McCarthy, L. (2008). In game room, in world: Reconnecting video game play to the rest of kids' lives. In K. Salen (Ed.), The ecology of games: Connecting youth, games, and learning (pp. 41-66). Cambridge, MA: The MIT Press.

Stevens, R., Wineburg, S., Herrenkohl, L., \& Bell, P. (2005). The comparative understanding of school subjects: Past, present and future. Review of Educational Research, 75(2), 125-157.

Super Smash Bros. Melee: Instruction booklet. (2001). Redmond, WA: Nintendo of America Inc.

Vygotsky, L. S. (1962). Thought and language. Cambridge, MA: MIT Press.

Wineburg, S., Mosborg, S., Porat, D., \& Duncan, A. (2007). Common belief and the cultural curriculum: An intergenerational study of historical consciousness. American Educational Research Journal, 44(1), 40-76. 